\title{
February 24 Highlights
}

\section{Verbal fluency in dementia diagnosis}

Duff Canning et al. investigated the diagnostic utility of 1-minute verbal fluency tests in 165 cognitively impaired memory clinic patients and 46 controls. Animal fluency discriminated all patient groups from controls. Letter $\mathrm{F}$ fluency ( $<4$ words) differentiated vascular from Alzheimer disease (AD).

see page 556

The accompanying editorial by Jeffrey L. Cummings notes that there is increasing use of short, standardized mental status questionnaires such as the Mini-Mental State Examination to provide brief, objective measures of mental status changes. The Duff Canning et al. report offers an interesting approach to this challenge, with comprehensive evaluations of two 1-minute tests: a category fluency measure-naming as many animals as possible; and a phonemic fluency testnaming as many words as possible beginning with the letter " $F$." They assessed five diagnostic groups including elderly controls, AD, and vascular dementia. Both category fluency and phonemic fluency provided useful information. Cummings points out that patients with aphasia and anomia will have difficulty with verbal fluency measures because of their primary language abnormality, and interpretation of verbal fluency measures is compromised by the presence of an aphasic disorder. Patients with major aphasia were excluded from this study. Educational levels were also very high in the patient groups studied.

see page 534

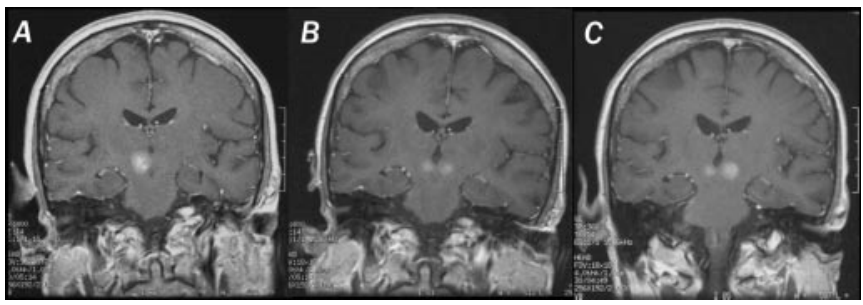

Enhancing PCNSL lesion(s) in red nucleus. Unilateral progressing to bilateral. See page 619.

\section{Primary central nervous system lymphoma (PCNSL): Side effects of treatment}

Harder et al. assessed cognitive function and neuroradiologic changes in 19 PCNSL patients treated with high-dose methotrexate-based chemotherapy and whole-brain irradiation. In contrast to 19 matched controls with hematologic malignancies, cognitive impairment was found in $63 \%$ together with white matter abnormalities or cortical atrophy in $78 \%$.

see page 544

Correa et al. documented mild to moderate cognitive dysfunction in a group of 28 survivors of PCNSL. Patients who received methotrexate-based chemotherapy and whole brain radiotherapy had more pronounced cognitive impairment than patients who received chemotherapy alone.

see page 548

In discussing these two articles and one recently published in Neurology (Lai et al., Neurology 2004;62:451-456), the accompanying editorial by Brian P. O'Neill notes that brain irradiation alone is unlikely to be responsible for neurocognitive decline of PCNSL patients. Rather, the neurocognitive decline is multifactorial with contributions of the disease itself and age-related comorbidity, in addition to the effects of treatment. Both whole brain radiotherapy and high-dose methotrexate-based chemotherapy, the two most commonly employed treatments, have a risk of neurotoxicity that increases with patient age. The pathogenesis of PCNSL is not well understood. Advances in treatment await a better understanding of the basic biology of this tumor.

see page 532 
- Stroke, cardiovascular disease, and death after triptans

Hall et al. studied 63,575 migraine patients; 13,664 had been prescribed a triptan. Their results suggest that, in general practice, triptan treatment in migraine does not increase the risk of stroke, myocardial infarction, cardiovascular death, ischemic heart disease, or mortality. However, triptans are prescribed to those less at risk of these events.

see page 563

\section{Beta-interferon and liver injury in} MS

Tremlett et al. found a higher incidence of elevated aminotransferases in multiple sclerosis (MS) patients treated with beta-interferon than has been noted in previously reported clinical trials of IFN in MS.

see page 628

\section{VIDEO ALERT}

The following videos are posted online for this issue of Neurology:

- Bowtie and upbeat nystagmus evolving into hemi-seesaw nystagmus in medial medullary infarction: Possible anatomic mechanisms (K.-D. Choi, D.S. Jung, K.-P. Park, J.-W. Jo, J.S. Kim, Neurology 2004;62:663-665)

- Tractography for an arteriovenous malformation (Kei Yamada, Osamu Kizu, Hirotoshi Ito, and Tsunehiko Nishimura, Neurology 2004;62:669)

Access www.neurology.org and search for the article. Click on Video to view. 


\section{Neurology}

February 24 Highlights

Neurology 2004;62;530-531

DOI 10.1212/WNL.62.4.530

This information is current as of February 23, 2004

\section{Updated Information \&}

Services

Permissions \& Licensing

Reprints including high resolution figures, can be found at: http://n.neurology.org/content/62/4/530.full

Information about reproducing this article in parts (figures,tables) or in its entirety can be found online at:

http://www.neurology.org/about/about_the_journal\#permissions

Information about ordering reprints can be found online:

http://n.neurology.org/subscribers/advertise

Neurology ${ }^{\circledR}$ is the official journal of the American Academy of Neurology. Published continuously since 1951, it is now a weekly with 48 issues per year. Copyright. All rights reserved. Print ISSN: 0028-3878. Online ISSN: 1526-632X.

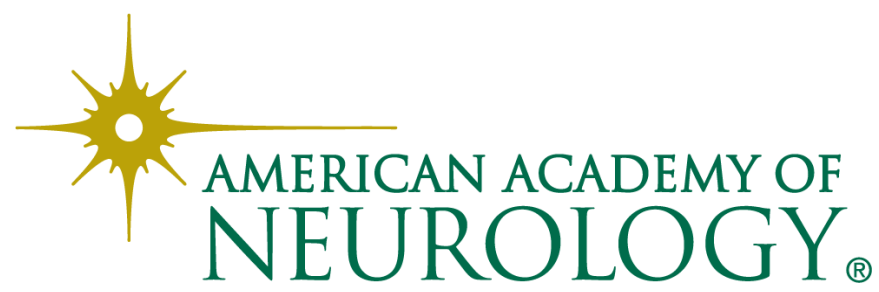

